\title{
CARACTERIZAÇÃO HIDROLÓGICA DOS SISTEMAS LACUSTRES DO ARQUIPÉLAGO DE ANAVILHANAS COM BASE EM SENSORIAMENTO REMOTO
}

\author{
HYDROLOGICAL CHARACTERIZATION OF ANAVILHANAS ARCHIPELAGO LAKE SYSTEMS \\ BY REMOTE SENSING
}

\section{Vanessa Cunha SILVA, Keila Pereira ANICETO, Rogério Ribeiro MARINHO, Naziano Pantoja FILIZOLA}

Universidade Federal do Amazonas. Avenida General Rodrigo Octavio Jordão Ramos, 1200 - Coroado I, Manaus - AM. E-mails: wanessavc01@gmail.com; keilaniceto@ufam.edu.br; rogeo@ufam.edu.br; nazianofilizola@ufam.edu.br

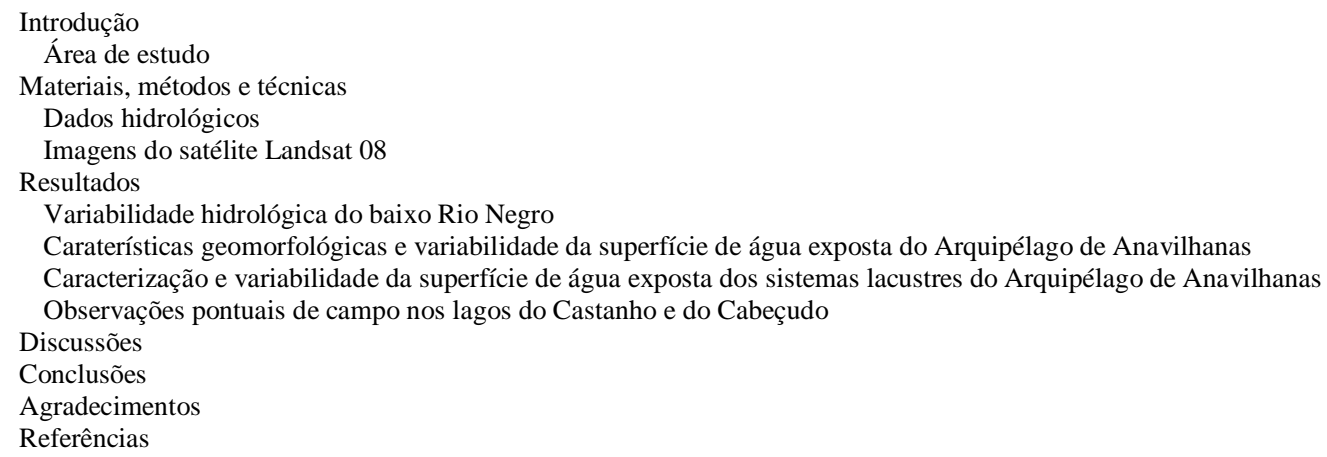

RESUMO - Este estudo caracterizou os sistemas lacustres do Arquipélago de Anavilhanas e avaliou a variação espacial da superfície de água em condições próximas as médias fluviométricas interanuais para cada período, utilizando imagens do Landsat 08 e dados fluviométricos do Rio Negro. A variação sazonal observada para todo o arquipélago foi na ordem de 10\%. Para os sistemas lacustres e áreas de "águas mortas" foi de 17\%. Para 447 lagos identificados, $46 \%$ possuem conexão com os canais do arquipélago durante o período de águas baixas e 54\% ficam isolados neste período. Foram apontados três domínios (A, B, C) para o Arquipélago. No domínio A (montante) o rio é relativamente estreito e as ilhas e lagos são menores. No domínio B (centro) o rio é relativamente mais largo e as ilhas e lagos são de grandes extensões. No domínio C (jusante) o rio apresenta largura semelhante ao domínio B e as ilhas estreitas, alongadas e sinuosas com lagos alongados e abertos. $\mathrm{O}$ domínio $\mathrm{C}$ apresentou menor variação sazonal e um maior número de lagos conectados, o que pode estar associado às características geomorfológicas e as condições hidráulicas dadas pela influência do barramento hidráulico do Rio Solimões.

Palavras-chave: Rio Negro; Geomorfologia fluvial; Sensoriamento remoto.

\begin{abstract}
This study characterized the Anavilhanas Archipelago lake systems and evaluated the spatial variation of the water surface under conditions close to the interannual fluviometric averages for each period, using Landsat 08 images and Rio Negro fluviometric data. The seasonal variation observed for the entire archipelago was around 10\%. For lake systems and "dead water" areas it was $17 \%$. For 447 lakes identified, $46 \%$ are connected to the archipelago canals during the low water period and 54\% are isolated during this period. Three domains (A, B, C) were pointed to the Archipelago. In domain A (upstream) the river is relatively narrow and the islands and lakes are smaller. In domain B (center) the river is relatively wider and the islands and lakes are large. In domain $\mathrm{C}$ (downstream) the river is similar in width to domain B and the narrow, elongated and winding islands with elongated and open lakes. The $\mathrm{C}$ domain presented less seasonal variation and a larger number of connected lakes, which may be associated with the geomorphological characteristics and hydraulic conditions given by backwater effect of the Solimões River.
\end{abstract}

Keywords: Negro River; Fluvial geomorphology; Remote sensing.

\section{INTRODUÇÃO}

O Arquipélago de Anavilhanas está localizado no baixo curso do Rio Negro, o principal afluente da margem esquerda do Rio Amazonas e maior rio de águas pretas da Bacia Amazônica. Tratase de um complexo sistema fluvial de ilhas com lagos em seu interior, constituídas por sedimentos finos e recobertas por vegetação, onde durante o período de águas altas são completamente inundadas formando os igapós (Latrubesse \& Franzinelli, 2005). Este arquipélago faz parte de uma área protegida no estado do Amazonas denominada de Parque Nacional de Anavilhanas, com mais de 350.000 hectares. Apresenta relevância internacional para a manutenção da biodiversidade reconhecida por meio da convenção Ramsar, que trata das zonas úmidas do planeta (MMA, 2018).

De acordo com Latrubesse \& Franzinelli (2005) as ilhas de Anavilhanas correspondem a $40,6 \%$ da área total do arquipélago, sendo que os 
lagos e as porções de "águas mortas" ocupam aproximadamente 25,9\% do arquipélago. Estes lagos e os canais foram interpretados por Marinho et al.. (2017a) como os setores mais afetados por eventos climáticos extremos, nesta região. Destaca-se também que, os sistemas de igapós assim como os de Anavilhanas, apresentam biota altamente sensível às mudanças no ciclo hidrológico, ocasionadas por mudanças climáticas ou represamento do rio (Junk et al., 2015).

Deste modo, a importância da realização de estudos hidrológicos e geomorfológicos nesta região se dá principalmente em virtude da recorrência de eventos extremos, especialmente a partir do ano 2005, das intervenções previstas em sua área de influência e para dar suporte à gestão sustentável do parque. Pois, estudos recentes têm demonstrado que os eventos hidrológicos extremos estão sendo registrados com maior frequência nos últimos anos na região Amazônica (Marengo et al., 2011; Marengo \& Espinoza, 2016). Além disso, encontra-se em andamento o estudo (EIA/RIMA) para construção da usina hidrelétrica de Bem Querer no Rio Branco, maior afluente do Rio Negro, cujas águas alcançam o arquipélago (MME/EPE, 2017; EPE, 2019).

Destaca-se, que a instalação de uma hidrelétrica pode ocasionar uma série de interferências no regime hidrológico e no ecossistema de uma bacia, que não se restringem apenas a seu ponto de implantação (Fearnside, 2015). Tais impactos estão associados à alteração no aporte de sedimentos, modificação da geometria hidráulica do rio, crescimento maciço de macrófitas aquáticas, deteriorização da qualidade da água, impactos ao balanço total de $\mathrm{CO}_{2}$, perda de espécie de plantas e animais, entre outros impactos já observados em barragens construídas na região Amazônica (Junk \& Mello, 1990; Assahira et al., 2017; Fearnside, 2015; Latrubesse et al., 2017), que podem ser ainda mais agravantes se associados a eventos extremos.

Face ao contexto acima descrito, uma das dificuldades para o melhor conhecimento do sistema hidrológico no arquipélago é a ausência de dados na região. Devido principalmente às extensas dimensões do parque, as dificuldades logísticas de acesso e custo operacional, na região de Anavilhanas há uma baixa densidade de estações hidrométricas e as séries de dados são de curta duração. Em geral, são usados os dados registrados na estação fluviométrica do porto de Manaus localizada $143 \mathrm{~km}$ a jusante. No entanto, Manaus sofre com o efeito de barramento hidráulico do rio Solimões sobre o Negro, descrito por Meade et al. (1991) e por Filizola et al. (2011). Neste sentido, não se conhece como esse efeito se propaga para montante, bem como existem poucos ou quase nenhum dado que trate sobre a hidrogeomorfologia de Anavilhanas.

Nesta perspectiva, o Sensoriamento Remoto constitui ferramenta de uso consolidado como alternativa para o preenchimento das lacunas de dados, especialmente nos estudos voltados a análises temporais sobre grandes áreas. É uma ferramenta que possibilita o dimensionamento e a visualização espacial dos fenômenos estudados, como observado nos trabalhos de Latrubesse \& Franzinelli (2005); Gentirana et al. (2009); Gentirana (2009); Zani (2013); Cremon (2016); Almeida-Filho et al. (2016); Marinho et al. (2017a); Marinho et al. (2017b); Muniz et al. (2017), Marinho et al. (2019) entre outros, desenvolvidos nas bacias do Rio Negro e do Rio Branco.

Com o uso desta técnica, trabalhos anteriores (Almeida-Filho et al., 2016; Marinho et al., 2017a) mapearam e quantificaram a variação espacial da superfície de água exposta no Arquipélago de Anavilhanas utilizando imagens dos sensores: Landsat 05 (sensor TM) em dois períodos distintos do ciclo hidrológico além de testar outros produtos como imagens do satélite de abertura sintética ALOS-PALSAR, para avaliar eventos extremos na região. No entanto, eventos extremos correspondem a condições de exceção. Como referência mais propícia para estudos de manejo de ecossistemas, biodiversidade e mesmo climáticos, os períodos próximos das médias fluviométricas interanuais são mais adequados. Assim, este tipo de mapeamento constitui um desafio numa região como Anavilhanas. Em especial que seja correlacionado fazendo-se uso conjunto de dados fluviométricos in situ e dados de sensores remotos. Ademais, não há registros de estudos hidrológicos ou geomorfológicos sendo direcionados especificamente aos sistemas lacustres deste arquipélago.

Diante deste cenário, este estudo buscou realizar uma caracterização dos sistemas lacustres do Arquipélago de Anavilhanas e avaliar qual a variação espacial da superfície de água exposta entre águas altas e baixas a partir de 
Sensoriamento Remoto. Foram utilizadas imagens Landsat 08 (sensor OLI), tendo como base o ano hidrológico 2016-2017. O ano hidrológico foi escolhido, em virtude da disponibilidade de imagens em datas em que o Rio Negro apresentou cota similar às cotas médias interanuais para cada período hidrológico, não sendo necessariamente a cota máxima registrada no período analisado. Deste modo, buscou-se documentar e referenciar dados in situ com dados de sensores remotos em períodos hidrológicos "normais" do Rio Negro.

\section{Área de Estudo}

O Rio Negro está localizado na porção noroeste da Bacia Amazônica e sua foz localizase no Rio Solimões em frente a cidade de Manaus (AM), a partir de onde o rio principal da bacia, passa a denominar-se Amazonas. O clima da região do baixo Rio Negro é caracterizado como tropical chuvoso, ou equatorial com temperaturas altas com médias mensais de 25 a $28^{\circ}$, com amplitude anual menor que $3^{\circ}$ e precipitação pluvial abundante e bem distribuída durante todo o ano (Ayoade, 1996).

As precipitações anuais da Bacia do Rio Negro apresentam média de 2000 a $2200 \mathrm{~mm}$ (Sombroek, 2001), entretanto, em determinadas áreas na fronteira entre Brasil, Venezuela e Colômbia esse valor pode chegar a $3500 \mathrm{~mm}$ (Fisch et al., 1998). O Rio Negro possui uma descarga líquida média anual de aproximadamente $29.000 \mathrm{~m}^{3} / \mathrm{s}$ e $696.000 \mathrm{~km}^{2} \mathrm{de}$ área de drenagem (Filizola, 1999; Filizola \& Guyot, 2009). Apresenta regime do tipo equatorial, com um pico de águas altas mais acentuado no meio do ano (Molinier et al., 1996), águas pobres em sólidos suspensos e cor marrom avermelhada (pretas quando em grande volume) em decorrência da presença de substâncias húmicas lixiviadas de solos podzólicos da região (Junk et al., 2015). É importante destacar que na região do baixo Rio Negro, incluindo a área em estudo, os níveis sofrem influência do barramento hidráulico ocasionado pelo Rio Solimões (Meade et al., 1991; Filizola et al., 2011). O que faz com que estes dois rios apresentem comportamento semelhante no regime hidrológico de Manaus até a região de Moura, próximo da foz do rio Branco.

Na região de Anavilhanas (Figura 1), o Rio Negro apresenta um padrão "anabranching", com uma tipologia de múltiplos canais separados por ilhas, que possuem lagos interiores (Latrubesse \& Stevaux, 2015).

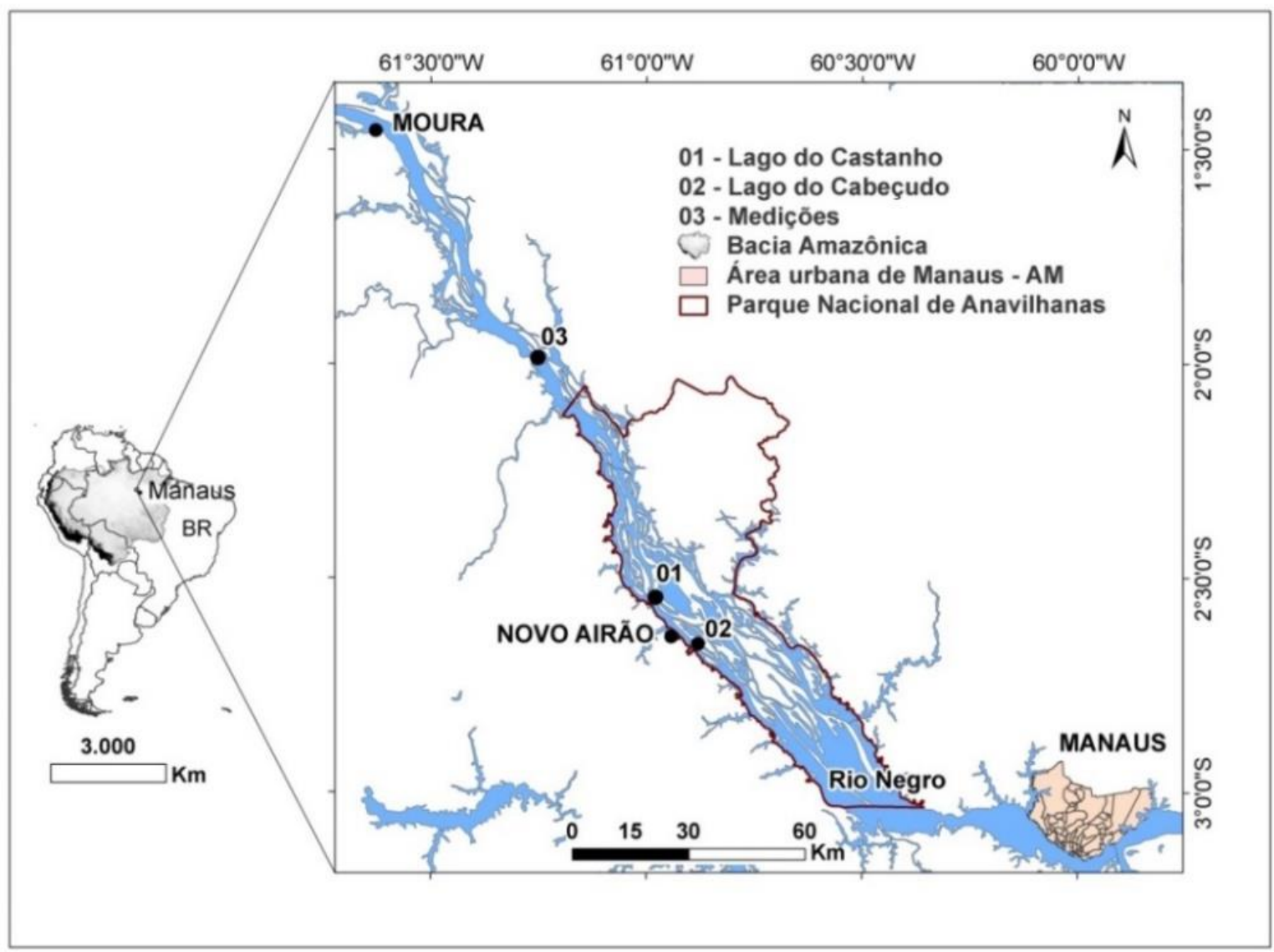

Figura 1 - Localização da área de estudo, com a indicação dos pontos de investigação (Lago do Castanho, do Cabeçudo e ponto de medições de descarga líquida). 
As ilhas são compostas por sedimentos finos e cobertas por vegetação. Trata-se de um ecossistema de florestas baixas, pouco diversificadas que durante os períodos de águas altas são inundadas formando os igapós, uma nomenclatura regional dada às florestas sazonalmente inundadas pelos rios de águas pretas (Latrubesse \& Franzineli, 2005; Ab'saber, 1998; Piedade et al., 2005; Prance, 1980).

Já durante os períodos de águas baixas, é registrada a ocorrência de extensas barras fluviais arenosas ao longo dos canais que compõem o complexo de ilhas da região (Alves, 2013)

\section{MATERIAIS E MÉTODOS}

\section{Dados Hidrológicos}

A caracterização hidrológica foi realizada a partir da série histórica de cotas fluviométricas da estação do Porto de Manaus, correspondente ao período de 1903 a 2018 e de Novo Airão correspondente ao período de 2014 a 2018.

Os dados foram adquiridos na plataforma digital do Sistema Nacional de Informações sobre Recursos Hídricos - SNIRH (www.snirh.gov.br). Posteriormente, foram calculados os níveis médios históricos que serviram de base na seleção das imagens de satélites.

Medições da descarga líquida, área molhada, largura, profundidade e velocidade, foram realizadas em uma seção transversal do Rio Negro localizada à montante de Anavilhanas (Figura 1). Os dados foram coletados em novembro de 2016 e maio de 2017 com o uso de um Perfilador Doppler Acústico de Corrente (ADCP) operando na frequência de $600 \mathrm{kHz}$, conectado a um receptor DGPS.

O Software utilizado para aquisição e processamento dos dados deste equipamento foi o WinRiver II da RD Instruments. As medições foram realizadas seguindo as recomendações da ANA (2014) e de Filizola et al. (2009).

\section{Imagens Do Satélite Landsat 08}

O Landsat 08, lançado em 2013, é o oitavo satélite de um projeto desenvolvido pela Administração Nacional de Aeronáutica e Espaço (NASA), dedicado exclusivamente à observação dos recursos naturais terrestres, cujas observações foram iniciadas na segunda metade da década de 60. Apesar do surgimento de novos programas e do avanço nas técnicas de sensoriamento remoto, a série Landsat mantém sua importância em destaque devido seu acervo histórico e a contínua atualização tecnológica com a manutenção de características importantes (INPE, 2019).

O Landsat 08 apresenta órbita a circular, polar, heliossíncrona, a $705 \mathrm{~km}$ de altitude e inclinação de $98,2^{\circ}$. O seu sensor OLI captura imagens em 9 bandas espectrais com 30 metros de resolução espacial, incluindo uma faixa pancromática com 15 metros de resolução espacial, fornece dados com resolução temporal de 16 dias (USGS; INPE, 2019).

No uso de técnica de sensoriamento remoto óptico, duas regiões espectrais possuem melhor capacidade de delimitar áreas com a presença de corpos d'água, o infravermelho próximo e o infravermelho médio (Jensen, 2009).

Nesses intervalos espectrais a boa capacidade de mapeamento dos corpos d'água ocorre devido à grande quantidade de energia de fluxo radiante absorvida pela água.

Este fator faz com que em imagens de sensores que operam nestes comprimentos de onda, áreas cobertas com água possuam menor resposta em relação às áreas de terra firme.

Porém, quando o corpo d'água possui uma quantidade razoável de componentes opticamente ativos, como sedimentos em suspensão, o infravermelho próximo (NIR) não é absorvido totalmente, tornando assim o infravermelho médio (SWIR) o comprimento de onda mais apto para se trabalhar com a diferenciação entre áreas de terra firme e água.

Sendo assim, para este trabalho foram utilizadas as bandas correspondentes ao infravermelho próximo do satélite Landsat 08 (sensor OLI), obtidas em plataforma digital do Serviço Geológico Americano - USGS.

A seleção das imagens baseou-se nas datas com menor cobertura de nuvens e na variação média interanual entre os períodos de águas altas e baixas do Rio Negro, observados na estação fluviométrica do Porto de Manaus.

A variação observada nas cotas do Rio Negro entre as imagens de 30/07/2017 (águas altas) e de 15/10/2016 (águas baixas) foi de $9,37 \mathrm{~m}$, sendo 22 $\mathrm{cm}$ acima da variação média interanual observada na série histórica, que é de 9,59 m. (Tabela 1).

Para a identificação da área correspondente à superfície de água exposta, inicialmente as bandas analisadas foram reprojetadas para a projeção Universal Transversa de Mercator (UTM), Datum WGS 1984, zona 20S. 
Tabela 1 - Imagens selecionadas. Fonte: Serviço Geológico dos Estados Unidos - USGS (glovis.usgs.gov/).

\begin{tabular}{c|c|c|c|c|c|c}
\hline Missão & Data & Banda & $\begin{array}{c}\text { Resolução } \\
\text { espacial }\end{array}$ & $\begin{array}{c}\text { Cota no Rio Negro } \\
\text { (Manaus/Novo Airão) }\end{array}$ & \multicolumn{2}{c}{$\begin{array}{c}\text { Cota Média Histórica } \\
\text { (Manaus) }\end{array}$} \\
\hline Landsat 08 & $15 / 10 / 2016$ & 05 & $30 \mathrm{~m}$ & $18,26 \mathrm{~m} / 7,81 \mathrm{~m}$ & Águas baixas & $18,21 \mathrm{~m}$ \\
\hline Landsat 08 & $30 / 07 / 2017$ & 05 & $30 \mathrm{~m}$ & $27,63 \mathrm{~m} / 17,03 \mathrm{~m}$ & Águas altas & $27,80 \mathrm{~m}$ \\
\hline
\end{tabular}

Posteriormente a classificação foi executada conforme proposta de Zani et al. (2010), que consiste da operação de fatiamento (slicing) dos números digitais da banda 05 do Landsat 08 para classificar áreas como água e não água. Em seguida as imagens geradas foram vetorizadas e as áreas foram quantificadas em software SIG.

A quantificação dos lagos presentes no Arquipélago e o tipo de conexão que estes possuem com o canal principal foi realizado por interpretação visual nas imagens Landsat do ano de 2016.

\section{RESULTADOS}

\section{Variabilidade Hidrológica do Baixo Rio Negro}

A partir dos registros da série histórica da estação do Porto de Manaus (1903-2018) observa-se que o Rio Negro apresenta as cotas máximas entre os meses de maio a julho com pico de águas altas registrado predominantemente no mês de junho.

As cotas mínimas ocorrem entre os meses de outubro a janeiro, com mínimo predominantemente entre os meses de outubro e novembro. A variação média entre os períodos de águas altas e baixas nesta porção do Rio Negro é de 9,59 m, com cota média para águas altas de $27,80 \mathrm{~m}$ e a média para águas baixas de 18,21 m, conforme apresentado na figura 2. A estação de Novo Airão apresenta ainda uma série curta de dados (2014 a 2018), no entanto é possível verificar na figura 2 que segue o mesmo comportamento apresentado pela estação do Porto de Manaus.

Os dados da tabela 2 apresentam os resultados das medições hidrométricas realizadas durante os períodos de águas altas e baixas do Rio Negro no ano hidrológico analisado. A descarga líquida medida em maio de 2017 (águas altas) correspondeu 40.626 $\mathrm{m}^{3} / \mathrm{s}$. Já a descarga líquida medida em novembro de 2016 (águas baixas) foi de 17.676 $\mathrm{m}^{3} / \mathrm{s}$, cerca de 2,30 vezes menor do que a descarga observada durante as águas altas.

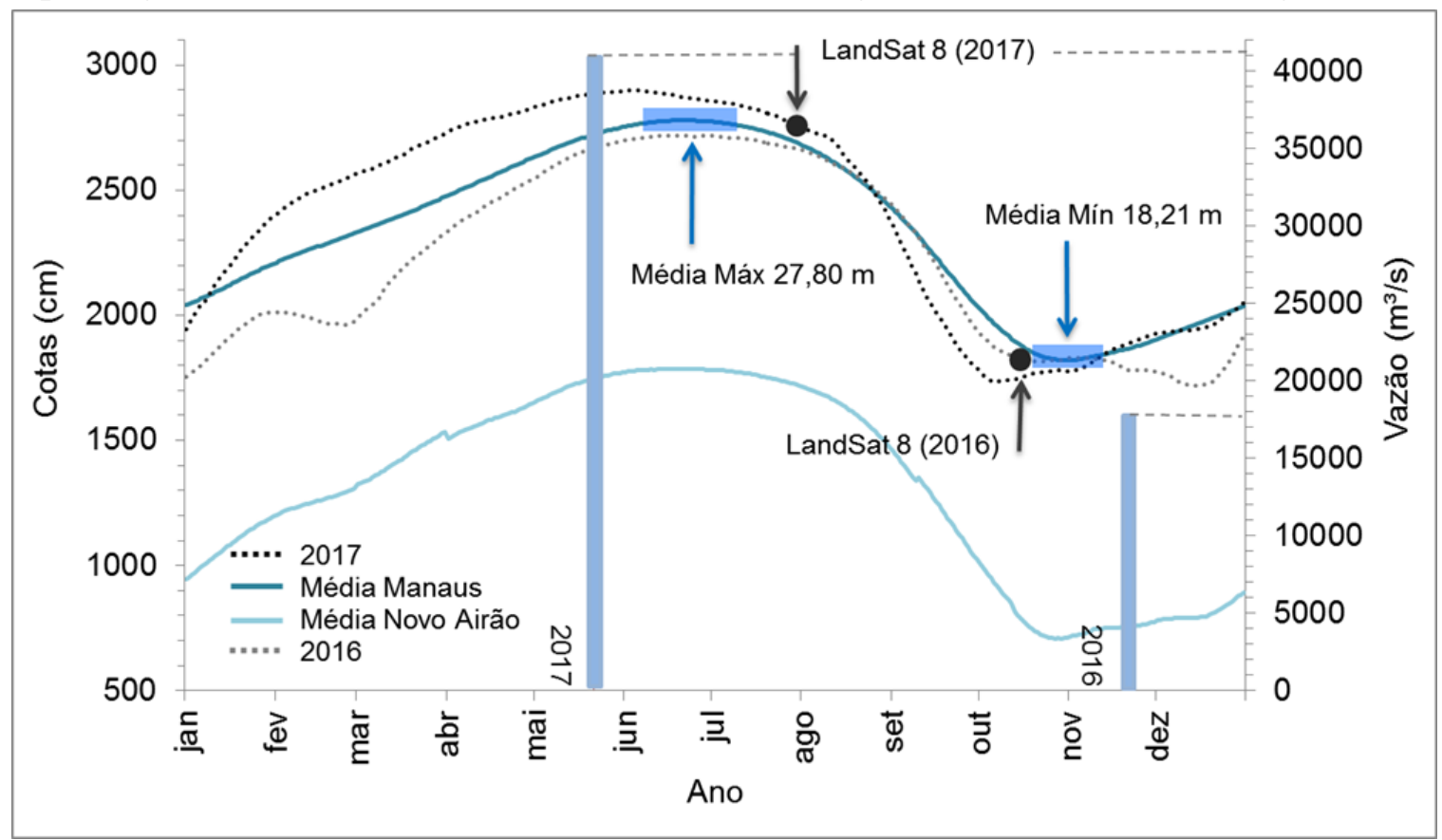

Figura 2 - Cotagrama com as cotas médias interanuais das estações fluviométricas do Porto de Manaus (1903 - 2018) e de Novo Airão (2014 - 2018). Cotas fluviométricas do ano hidrológico analisado (2016 - 2017) com destaque para a data das imagens Landsat 08 coletadas nos períodos hidrológicos semelhantes as médias de cada período, destacadas pelos retângulos azuis transparentes. Barras em azul correspondem às medições de descarga líquida realizadas no período de águas altas e baixas do Rio Negro em uma seção a montante do arquipélago (Figura 1). Ambas as estações possuem referência topográfica local. 
Tabela 2 - Dados hidrométricos adquiridos a montante de Anavilhanas (Figura 1) referenciados as cotas fluviométricas da estação de Novo Airão. Fonte: Marinho (2019).

\begin{tabular}{c|c|c|c|c|c|c|c|c}
\hline Data & Período & $\begin{array}{c}\text { Cota } \\
\text { N.A. }(\mathbf{m})\end{array}$ & $\begin{array}{c}\text { Vazão } \\
\left(\mathbf{m}^{3} / \mathbf{s}\right)\end{array}$ & $\begin{array}{c}\text { Velocidade média } \\
\text { do fluxo }(\mathbf{m} / \mathbf{s})\end{array}$ & $\begin{array}{c}\text { Área da } \\
\text { seção }\left(\mathbf{m}^{\mathbf{2}}\right)\end{array}$ & $\begin{array}{c}\text { Largura da } \\
\text { seção }(\mathbf{m})\end{array}$ & $\begin{array}{c}\text { Profundidade } \\
\text { média }(\mathbf{m})\end{array}$ & $\begin{array}{c}\text { Profundidade } \\
\mathbf{m a ́ x i m a}(\mathbf{m})\end{array}$ \\
\hline $11 / 16$ & Seca & 7,32 & 17.676 & 0.55 & 33.169 & 2.720 & 12 & 20 \\
\hline $5 / 17$ & Cheia & 18,13 & 40.626 & 0.70 & 60.234 & 2.797 & 22 & 30 \\
\hline
\end{tabular}

\section{Caraterísticas}

Geomorfológicas

Variabilidade da Superfície de Água Exposta do Arquipélago de Anavilhanas

O Arquipélago de Anavilhanas possui aproximadamente $140 \mathrm{~km}$ de extensão com largura variando de $5 \mathrm{~km}$ a $21 \mathrm{~km}$. De modo geral, é mais estreito a montante e mais largo na porção central e a jusante. Essa diferenciação também é observada nas características geomorfológicas e distribuição espacial das ilhas e lagos presentes. Com base nestas características e para fins de análise no presente estudo, o arquipélago foi subdividido em três domínios (A, B, C). O domínio A (Figura 3) apresenta, no contexto da região do estudo, largura do rio relativamente estreita, ilhas e lagos relativamente menores e em menor quantidade, os quais estão espacialmente concentrados nas margens mais côncavas. As ilhas apresentam formatos alongados com lagos internos de formatos variados, predominantes lagos com formatos estriados e de pequenas proporções relativas. $\mathrm{Na}$ região central do canal, durante as águas baixas emergem as barras arenosas.

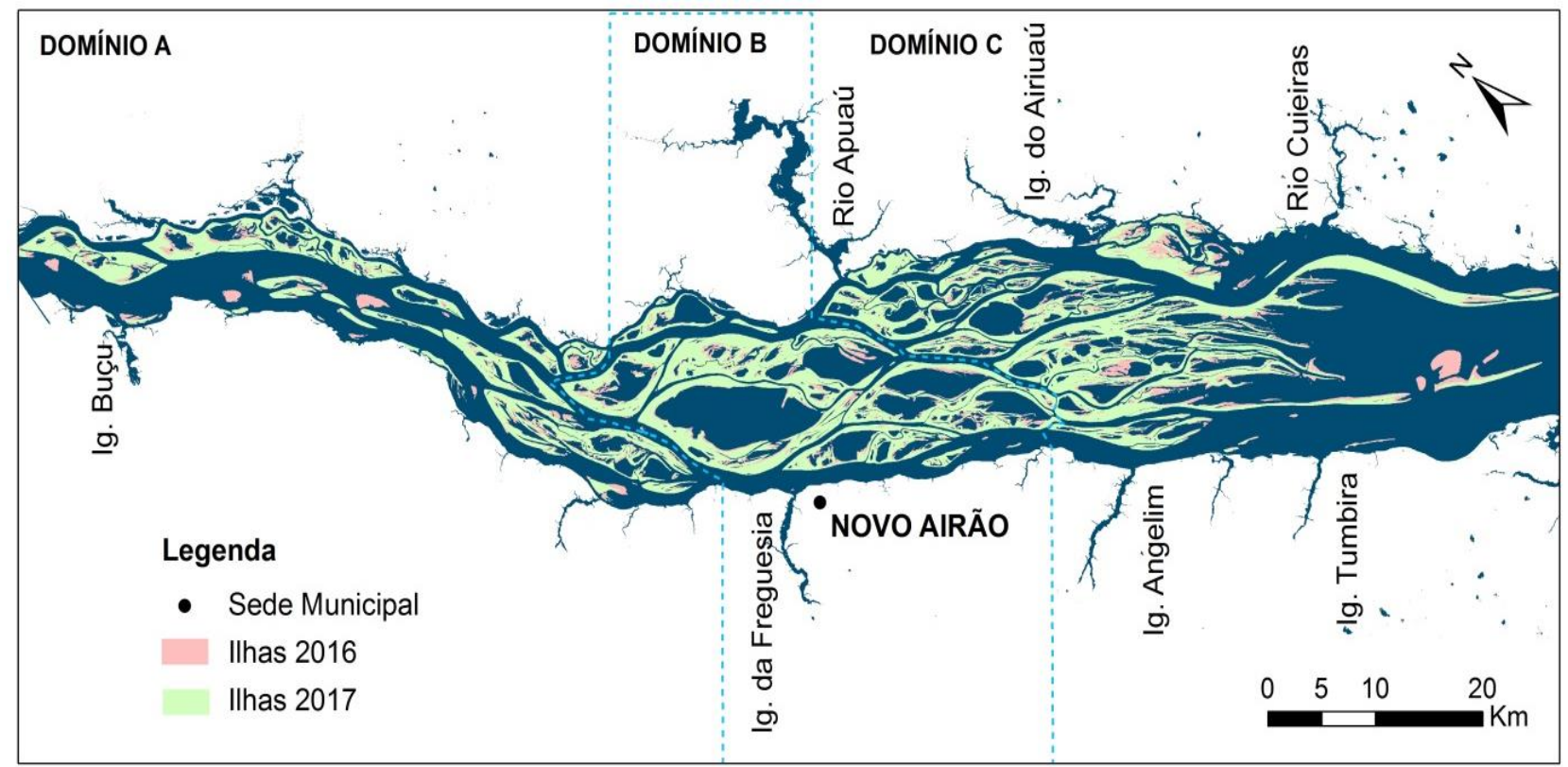

Figura 3 - Características geomorfológicas do Arquipélago de Anavilhanas observada no ano hidrológico 2016-2017. A área das ilhas é representada na cor verde para o ano de 2017 (águas altas) e na cor rosa para o ano 2016 (águas baixas). As listas tracejadas delimitam os domínios A, B e C.

O domínio B (Figura 3) é caracterizado por apresentar largura do canal relativamente maior que o domínio A, ilhas largas e lagos de grandes extensões, acompanhando o formato das ilhas em que estão inseridos. Nesta porção estão localizados os maiores lagos do arquipélago, sendo o lago do Apacú o maior deles, com aproximadamente $15 \mathrm{~km}$ de comprimento e $5 \mathrm{~km}$ de largura. O lago Apacú está conectado ao rio por meio de um canal na porção sul (jusante) durante todos os períodos hidrológicos, a exceção de eventos extremos de águas baixas, conforme observado no ano de 2010 por Marinho et al. (2017a).

O domínio C (Figura 3), por sua vez, apresenta largura semelhante ao domínio B. Em ambos ocorrem um maior número de afluentes ao longo do Arquipélago, conforme pode ser observado na figura 3 . No entanto, o domínio $\mathrm{C}$ apresenta ilhas estreitas, alongadas e sinuosas com comprimento alcançando até $55 \mathrm{~km}$. No geral, são registrados alguns lagos de formato arredondado, predominando aqueles de formato alongado e aberto. Na parte sul (jusante) ocorre o setor denominado por Latrubesse \& Franzinelli (2005) como área de águas mortas e ilhas com 
morfologia "fantasma".

A variabilidade média interanual de 9,59 metros entre águas altas e baixas do Rio Negro observada em Manaus é refletida nos aspectos da paisagem, espacialmente por meio da mudança nas áreas correspondentes à superfície de água exposta. Associada a essa variação média do nível do Rio Negro, observou-se uma variação de aproximadamente $163 \mathrm{~km}^{2}$ na superfície de água exposta, o que representa oscilação da ordem de
10\%. Durante as águas baixas de 2016 a superfície ocupada era de $1.342 \mathrm{~km}^{2}$ e nas águas altas essa área aumentou para aproximadamente $1.505 \mathrm{~km}^{2}$ (Figura 4).

Para o domínio A observou-se um aumento de $41,372 \mathrm{~km}^{2}$ de área $(+11,29 \%)$ entre as águas baixas de 2016 e as águas altas de 2017. No domínio B esse aumento correspondeu a 36,174 $\mathrm{km}^{2}$ de área $(+11,19 \%)$ e para o domínio $\mathrm{C}$ foi de $84,689 \mathrm{~km}^{2}(+10,65 \%)$ (Figura 4).

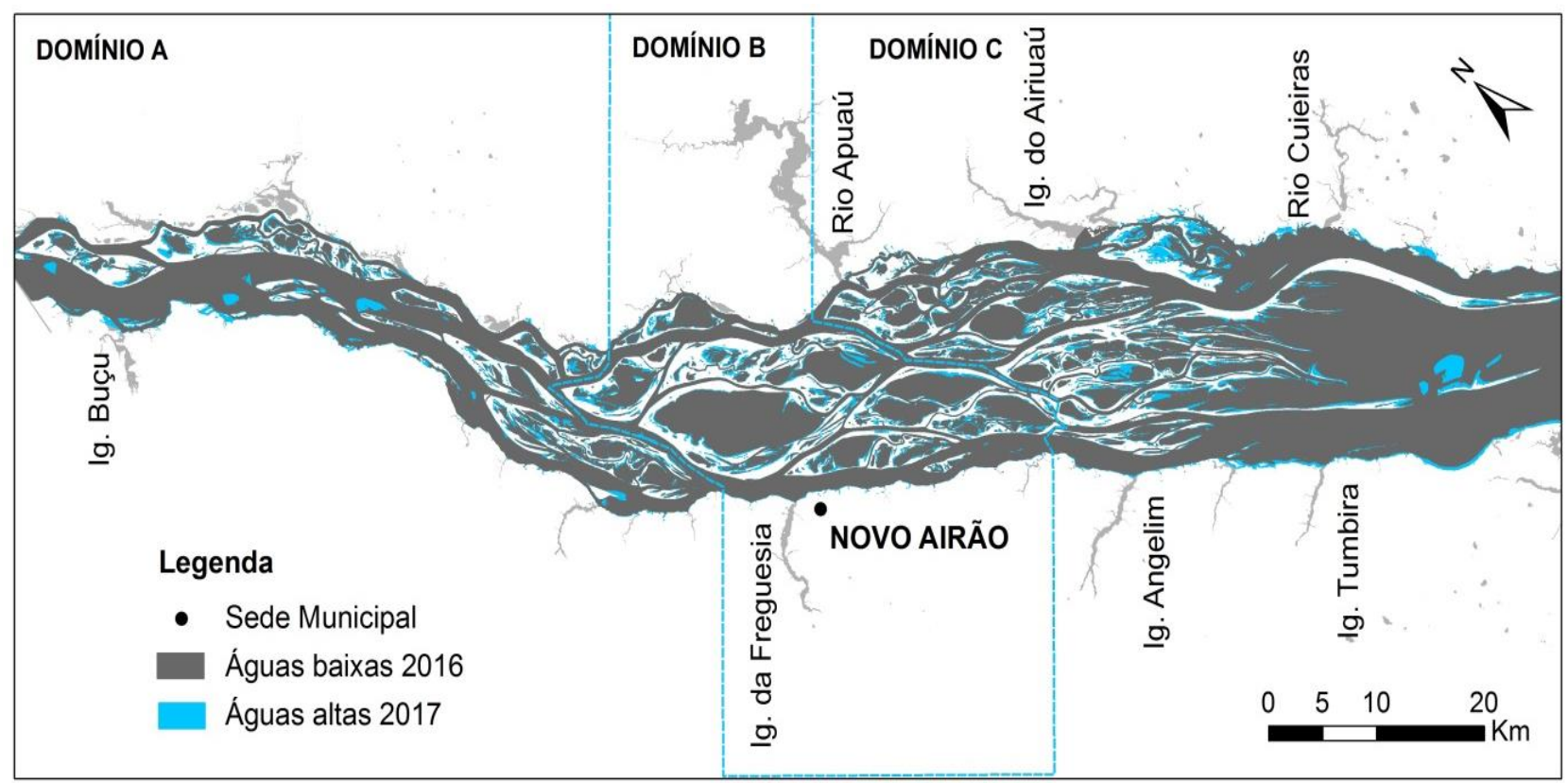

Figura 4 - Variação espacial da superfície de água exposta (cota de 9,59 metros) no Arquipélago de Anavilhanas observada no ano hidrológico 2016-2017. Na cor cinza está representada a superfície exposta durante o período de águas baixas (2016) e na cor azul a superfície exposta durante as águas altas (2017). As listas tracejadas delimitam os domínios subdivididos para o arquipélago.

Caracterização e Variabilidade da Superfície de Água Exposta dos Sistemas Lacustres do Arquipélago de Anavilhanas

O Arquipélago de Anavilhanas apresenta um complexo conjunto de lagos de diferentes dimensões e formatos, onde os maiores lagos identificados foram no domínio B. Com base na imagem Landsat 08 de 2016 (águas baixas) foram identificados no total a ocorrência de 447 lagos, 209 destes conectados aos principais e 238 isolados.

No entanto, destaca-se que essa quantidade é variável em relação ao período hidrológico, dependendo dos níveis do Rio Negro, alguns destes lagos conectam-se entre si formando somente um lago e durante as águas altas todo o sistema lacustre de Anavilhanas se conecta ao Rio Negro por meio dos igapós. Essa quantidade também é variável de acordo com a escala de detalhe, pois ocorrem lagos de pequenas dimensões, não mapeados na escala deste estudo
(Figura 5).

Os lagos conectados são predominantemente aqueles que apresentam maiores dimensões (Domínio B), enquanto os isolados são pequenos e localizados no entorno dos maiores. A conexão ocorre principalmente por canais estreitos dos lagos maiores para os canais principais, alguns destes lagos apresentam conexão secundária, ou seja, estão ligados a um lago que por sequência se conecta ao regime do arquipélago. Há ainda os setores de relativa baixa hidrodinâmica em função da geomorfologia das ilhas que estão inseridos e que são conectados de forma mais ampla ao regime dos canais principais. Destacase que estes pontos de conexão entre os lagos e os canais durante os períodos de águas baixas, ocorrem predominantemente na porção a jusante dos lagos em cerca de $66,51 \%$ deles. Em 27,75\% dos lagos a conexão ocorre nas laterais e apenas $5,74 \%$ dos lagos apresentam conexão na sua porção a montante. 


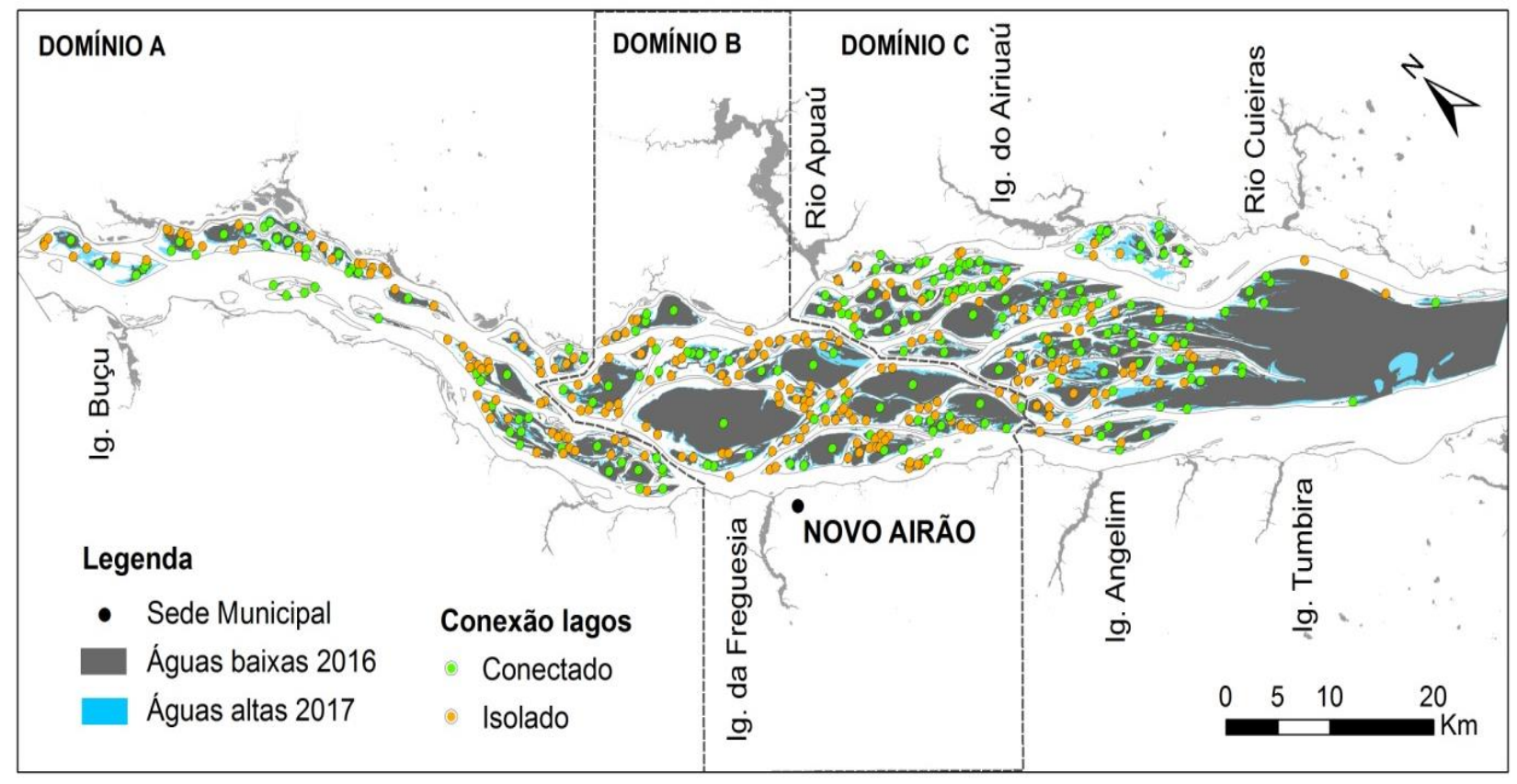

Figura 5 - Espacialização dos lagos presentes no Arquipélago de Anavilhanas com base no período de águas baixas de 2016, destacado na cor azul. Os pontos verdes representam os lagos que apresentam conexão com a dinâmica hidrológica dos principais canais neste período (águas baixas) e os pontos na cor laranja representam os lagos isolados. As linhas tracejadas delimitam os domínios subdivididos para o arquipélago.

No entanto, alguns destes apresentam ainda mais de um ponto de conexão em diferentes porções.

No período de águas baixas de 2016, no domínio A foram identificados 51 lagos conectados e 67 lagos isolados, no domínio B foram 45 lagos conectados e 102 lagos isolados, destaca-se que neste domínio ocorrem os maiores lagos do arquipélago e estes são predominantemente conectados, já no domínio C foram identificados 113 lagos conectados e 69 lagos isolados (Figura 5).

Associada a variação média de $9,59 \mathrm{~m}$ do nível do Rio Negro observada na estação de Manaus, observou-se um aumento de cerca de $114,86 \mathrm{~km}^{2}(+17,27 \%)$ na superfície de água exposta dos lagos e dos setores de águas mortas/baixa hidrodinâmica existentes no arquipélago entre 2016 (águas baixas) e 2017 (águas altas). Em 2016 essas áreas corresponderam a 550,071 $\mathrm{km}^{2}$ e em 2017 passaram para $664,931 \mathrm{~km}^{2}$ (Figura 6).

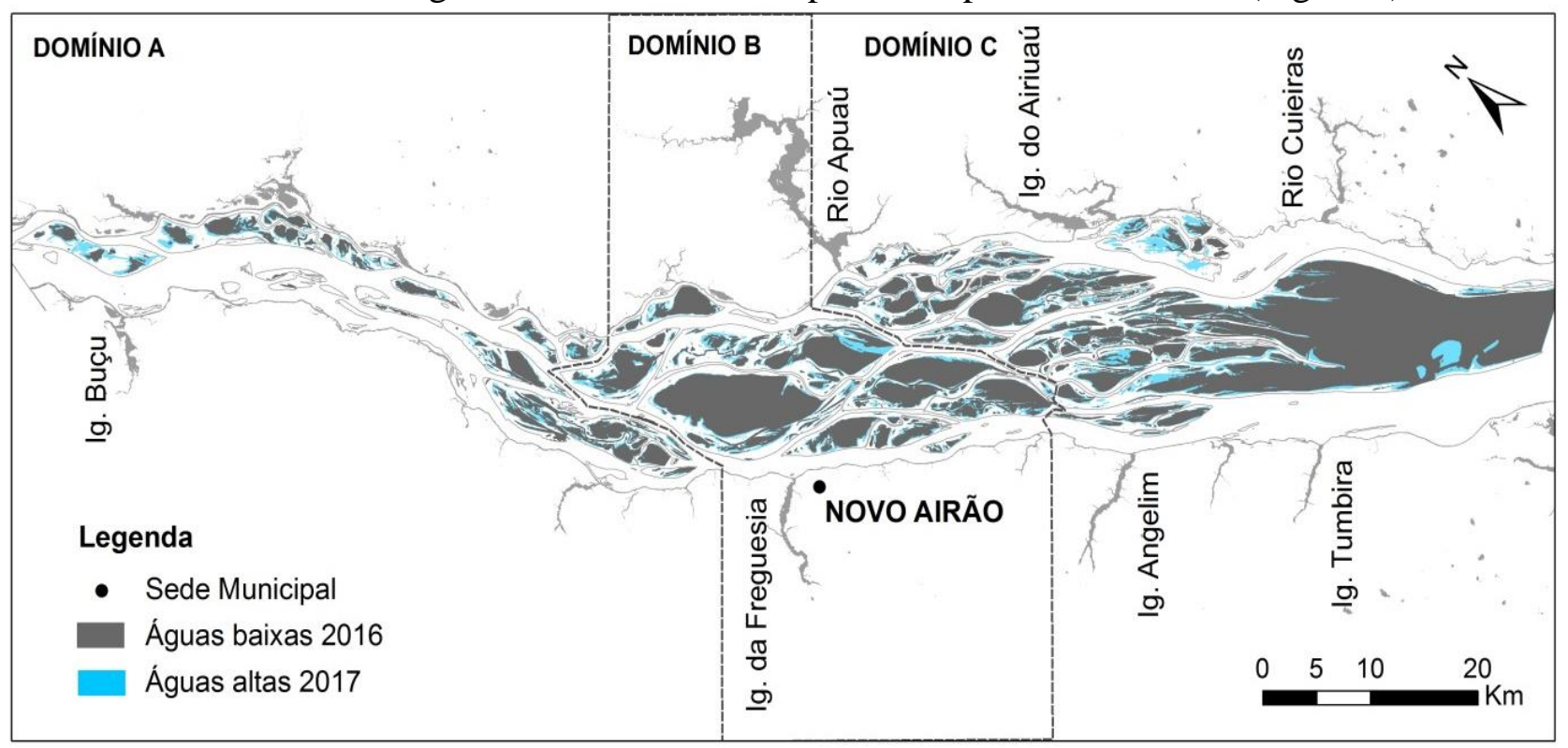

Figura 6 - Variação espacial da superfície de água exposta (de 9,59 metros) dos sistemas lacustres do Arquipélago de Anavilhanas observada no ano hidrológico 2016-2017. Na cor cinza está representa a superfície mapeada no período de águas baixas (2016) e na cor azul está mapeada a superfície observada no período de águas altas (2017). As listas tracejadas delimitam os domínios subdivididos para o arquipélago. 
No domínio A em 2016 (águas baixas) a superfície de águas expostas dos sistemas lacustres foi de 48,239 km² e em 2017 (águas altas) aumentou para $67,196 \mathrm{~km}^{2}(+28,95 \%)$. No domínio B em 2016 (águas baixas) essas áreas foram de 164,308 km² e em 2017 (águas altas) aumentou para $197,901 \mathrm{~km}^{2}(+16,97 \%)$.

Já no domínio C em 2016 (águas baixas) as áreas corresponderam a 337,524 km² e em 2017 (águas altas) aumentaram para $399,834 \mathrm{~km}^{2}$ $(+15,58 \%)$ (Figura 6).

Entre os três domínios é observado um decréscimo no percentual de variação de jusante para montante, sendo o domínio $\mathrm{C}$ o que menos apresentou variação. Esta situação pode estar refletindo as condições do barramento hidráulico exercido pelo Rio Solimões sobre o Rio Negro, conforme descrito por Meade et al. (1991) e Filizola et al. (2011).

Observações Pontuais de Campo nos Lagos do Castanho e do Cabeçudo

Visando checar em campo as observações feitas por imagem, foram visitados os lagos do Castanho e do Cabeçudo (Figura 7) no período de águas baixas de 2017 (Castanho) e no período de águas altas de 2018 (Cabeçudo).

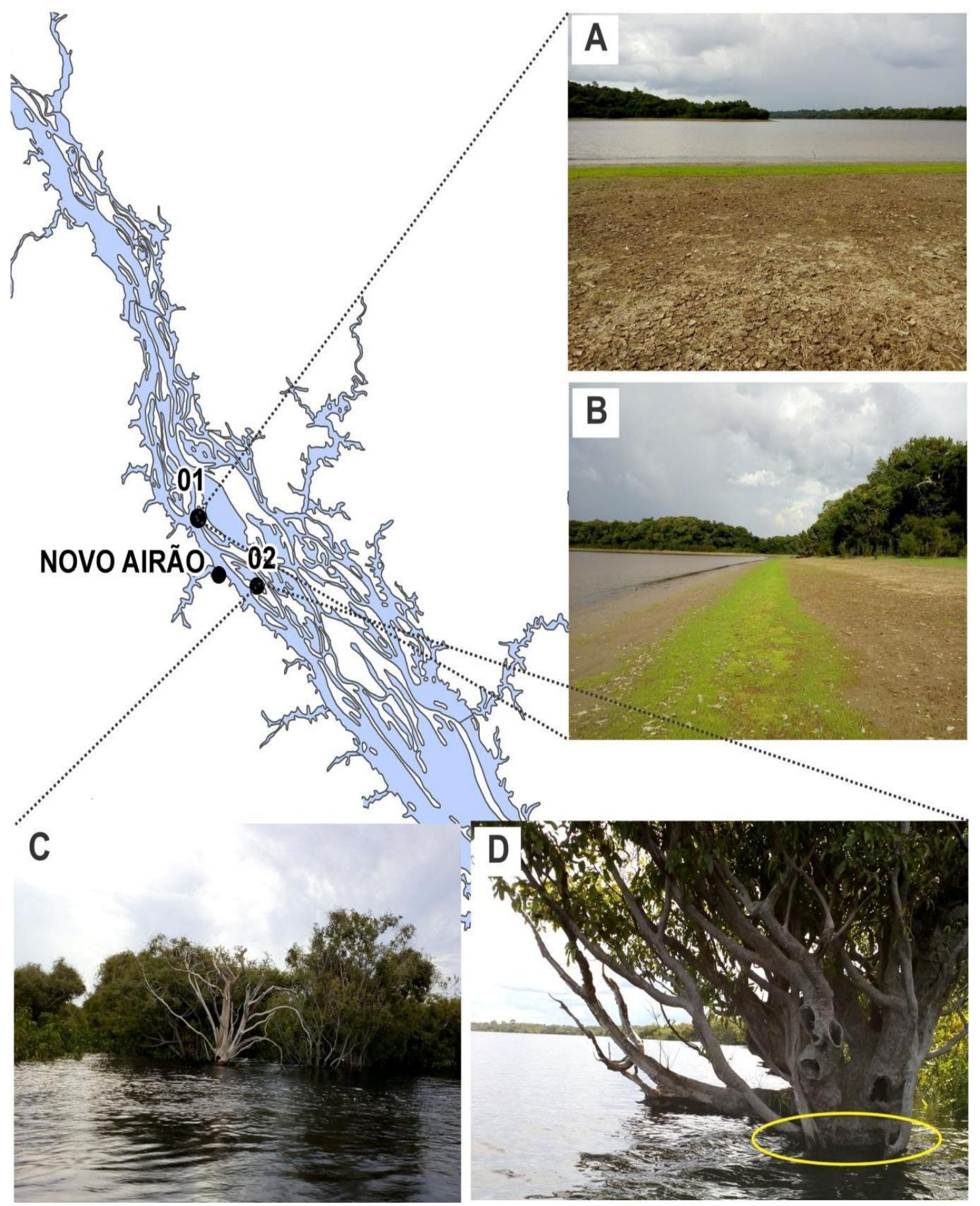

Figura 7 - A, B Lago do Castanho em 12/10/2017. C, D Lago do Cabeçudo em 26/04/2018. A área destacada em amarelo indica o nível máximo atingido. 
O lago do Castanho está localizado no domínio B, na margem direita do arquipélago, a montante da sede municipal de Novo Airão. Trata-se de um lago relativamente pequeno com formato alongado, isolado da dinâmica fluvial do canal principal durante as águas baixas, onde o acesso é feito por via terrestre adentrando as áreas vegetadas da ilha ao seu entorno. Entre os períodos de águas baixas de 2016 e águas altas de 2017 foi observada um aumento de cerca de $17 \%$ na superfície exposta do lago.

Em 2016 a superfície do lago correspondeu a uma área de $0,959 \mathrm{~km}^{2}$ e em 2017 passou para $1,169 \mathrm{~km}^{2}$. Em 12/10/2017 neste lago a cota do Rio Negro em Manaus foi de 17,43 m, o que corresponde a $0,78 \mathrm{~m}$ abaixo da cota média para o período de águas baixas, que costuma ocorrer neste período. As margens do lago estavam expostas, sendo caracterizada por uma combinação de sedimentos finos, fragmentos vegetais e a presença de vegetação rasteira tipo gramíneas (Figura 7A, B).
O Lago do Cabeçudo também está localizado no domínio B, na margem direita do arquipélago, a jusante da sede municipal de Novo Airão. Este lago apresenta tamanho médio, em relação ao anterior e formato arredondado, isolado da dinâmica fluvial do arquipélago nas águas baixas, mas durante as águas altas é conectado pelas áreas de igapó.

Entre as águas baixas de 2016 e as águas altas de 2017 foi observado um aumento de cerca de 9\% na superfície de água exposta do lago, onde a área passou de $1,903 \mathrm{~km}^{2}$ para $2,082 \mathrm{~km}^{2}$. Na ocasião da visita neste lago (26/04/2018), a cota do Rio Negro em Manaus foi de 25,80 m, o que corresponde $2,0 \mathrm{~m}$ abaixo da cota média para o período de máxima, que normalmente ocorre no mês de junho. Nesta cota, observou-se que os níveis do lago já se apresentavam significativamente elevados, alcançando a copa das árvores de seu entorno, deixando registrado nos seus troncos as marcas da altura máxima atingida pelas águas (Figura 7C, D)

\section{DISCUSSÕES}

Os resultados obtidos neste estudo indicam variações da ordem de $10 \%$ na superfície de água exposta observada, em condições de cota semelhante às médias interanuais. Em estudo semelhante, no entanto em condições extremas, Almeida-Filho et al. (2016) e Marinho et al. (2017a) utilizaram a banda 04 do sensor TM pertencente a missão Landsat 05 que apresenta as mesmas características do Landsat 08, com 30 metros de resolução espacial. No entanto, os autores citados, não tiveram a oportunidade de verificar as relações dos dados obtidos com informações de campo, e de comparar com dados hidrológicos de estação próxima, especialmente por conta da implantação recente (2013) de uma estação fluviométrica no arquipélago, especificamente na sede municipal de Novo Airão.

Durantes os eventos extremos de águas altas de 2009 e águas baixas de 2010, AlmeidaFilho et al. (2016) registraram variação da ordem de $53 \%$ na superfície de água exposta no arqui-pélago. Em estudo semelhante para o mesmo período, Marinho et al. (2017a) identificou uma variação semelhante e da ordem de $49 \%$. Quando comparadas estas variações de condições extremas com o identificado neste estudo (condições próximas das médias interanuais), observou-se diferença em torno de $40 \%$.

Os dados obtidos por Almeida-Filho et al. (2016) durante as águas altas de 2009 apresentaram aproximadamente $11 \%$ a mais de área inundada em relação ao observado neste estudo. Já durante as águas baixas de 2010, apresentaram uma diminuição de aproximadamente $32 \%$, conforme apresentado na tabela 3 .

No mesmo estudo, Almeida-Filho et al. (2016) também apresentaram resultados obtidos por imagens radar ALOS - PALSAR, para o período de águas altas de 2009, no qual identificaram cerca de $415 \quad \mathrm{~km}^{2}$ correspondentes à floresta inundada (igapó) no arquipélago, já a área correspondente à superfície de água exposta foi $1.534 \mathrm{~km}^{2}$, que somadas totalizam $2.048 \mathrm{~km}^{2}$, significando um aumento de cerca de $27 \%$ em área referente à vegetação inundada. Se adotado este mesmo percentual de áreas de vegetação inundadas para as águas altas de 2017, com dados deste estudo, tem-se uma área correspondente a 406 $\mathrm{km}^{2}$, totalizando $1.911 \mathrm{~km}^{2}$ de área $\mathrm{em}$ condições de cotas médias interanuais para o período.

Os resultados indicam diferenciações significativas em relação às ilhas e lagos que compõem o arquipélago. 
Tabela 3 - Dados de áreas de Anavilhanas obtidos por Sensoriamento Remoto.

\begin{tabular}{c|c|c|c}
\hline Situação & Data & Superfície de água livre & Referência \\
\hline Cota Média & Águas altas - 2017 & $1.505 \mathrm{~km}^{\mathbf{2}}$ & \multirow{2}{*}{ Este estudo } \\
\hline Cota Média & Águas baixas - 2016 & $1.342 \mathrm{~km}^{\mathbf{2}}$ & \\
\hline Evento Extremo & Variação & $\mathbf{- 1 6 3} \mathbf{~ k m}^{\mathbf{2}}$ & \\
\hline Evento Extremo & Águas baixas - 2010 & $1.700 \mathrm{~km}^{\mathbf{2}}$ & \multirow{2}{*}{ Almeida Filho et al. (2016) } \\
\hline & Variação & $\mathbf{- 7 9 5} \mathbf{~ k m}^{\mathbf{2}}$ & \\
\hline
\end{tabular}

Trabalhos anteriores também apontam boram com as definições dos domínios aqui diferenciações semelhantes em relação à apresentadas (Figura 8) (Cunha, 2017; geomorfologia das ilhas e lagos que corro- Latrubesse \& Franzinelle, 2005).

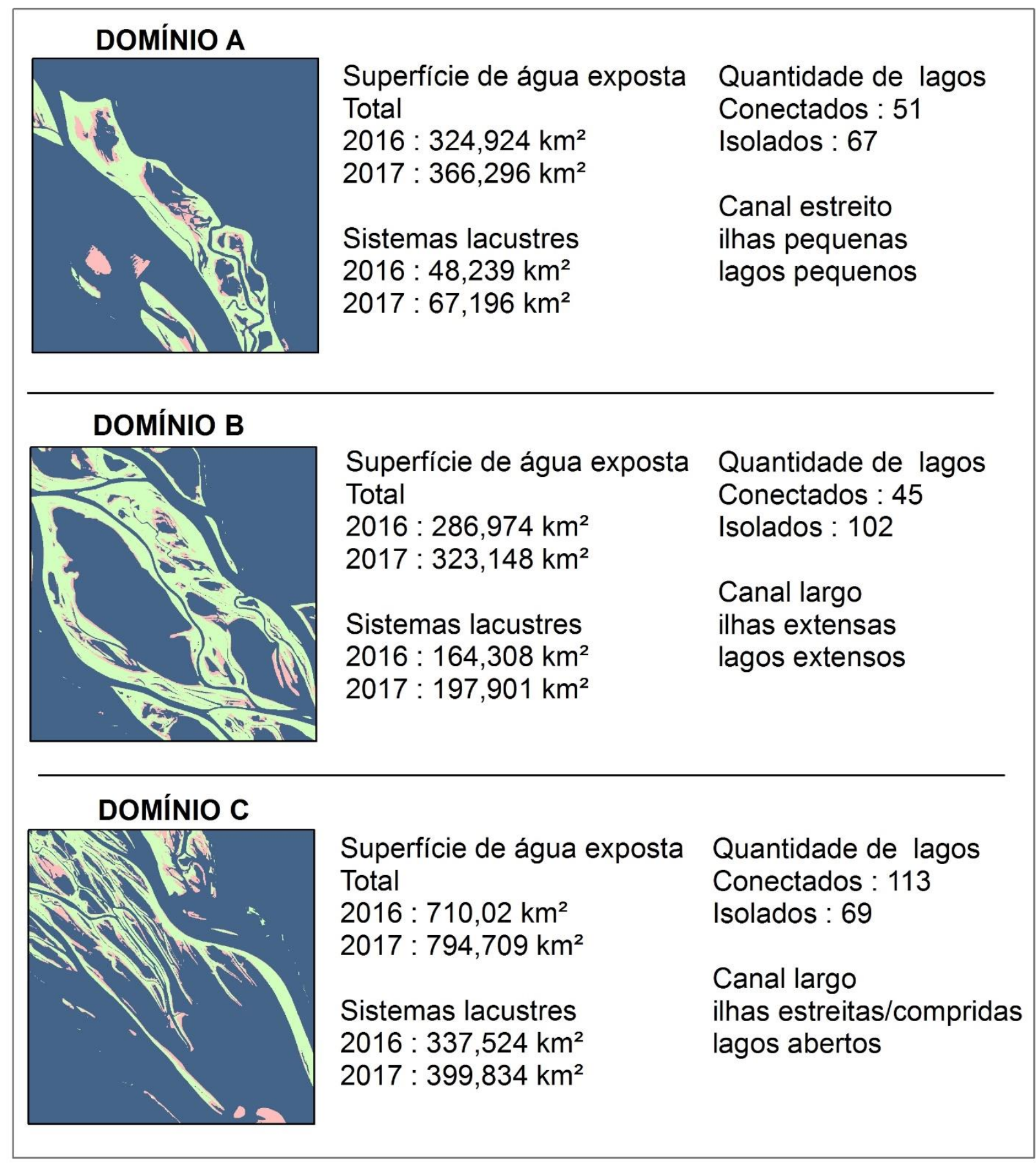

Figura 8 - Síntese das principais características observadas nos domínios A, B, C. Nos quadros à esquerda estão representados os tipos de ilhas e lagos predominantes para cada domínio. 
De acordo com Cunha (2017) nas porções de montante e central do arquipélago, aqui classifi-cadas como domínios A e B, as ilhas são relati-vamente mais altas e na porção a jusante, corres-pondente ao domínio C, apresentam menores elevações. Latrubesse \& Franzinelli (2005) também apontam para a altura das ilhas diminuído gradualmente de montante para jusante, além de modificações na vegetação, que passa de uma floresta arborizada inundada (floresta de igapó) para uma vegetação arbustiva baixa (Latrubesse \& Franzinelli, 2005).

Destaca-se que em relação ao tipo de conexão dos sistemas lacustres identificados, observou-se que o domínio $\mathrm{C}$ apresentou maior quantidade de lagos conectados enquanto que nos domínios A e B predominaram lagos isolados. $O$ percentual de variação da superfície de água exposta dos sistemas lacustres também foi inferior no domínio $C$. Acredita-se que essa singularidade seja resultado da geomorfologia dos lagos, predominantemente abertos, também podendo estar associado à altitude das ilhas, mais baixas nesta porção e sob condições hidrológicas vinculadas ao barramento hidráulico ocasionado pelo Rio Solimões sobre o Rio Negro, conforme discutido por Meade et al. (1991) e Filizola et al. (2011).

\section{CONCLUSÕES}

O Arquipélago de Anavilhanas está sujeito a uma grande amplitude de variação sazonal, mesmo sob condições regulares (médias fluviométricas diárias interanuais). Estas sazonalidades ocasiona uma série de modificações na paisagem ao longo destes períodos. Estas alterações impactam de modo diferente os lagos da região. Estes lagos também apresentam características geomorfológicas diferenciadas, aparentemente em função de condições hidrológicas dadas tanto pelos fluxos de montante, quanto pela influência do barramento hidráulico do Rio Solimões. Compreender a dinâmica hidrológica dos sistemas lacustres deste arquipélago constitui-se num desafio face às suas complexidades. $\mathrm{O}$ presente estudo mostrou características fora do contexto de eventos extremos que podem servir de referência (linha de base) para estudos de impacto tanto nos canais, quanto nos sistemas lacustres. Assim, resumidamente este estudo permitiu identificar que:

A variação sazonal média do Rio Negro encontrada, entre águas altas e baixas, no período estudado, foi da ordem de 9,6 m;

Associada à variação acima descrita, observou-se, em área, uma variação na ordem de $10 \%$ nas áreas correspondentes a superfície de água exposta do arquipélago.

Dentre os três domínios utilizados para análise, o domínio $\mathrm{C}$ (porção mais a jusante) apresentou menor variação de superfície de água exposta entre os períodos estudados nos sistemas lacustres. Esta característica pode estar relacionada às condições geomorfológicas das ilhas e as condições hidráulicas dadas pelo barramento hidráulico do Rio Solimões sobre o Rio Negro.

Verificou-se, portanto, que em área, sob condições de "normalidade", a variação é pequena no contexto geral, porém as consequências nos sistemas lacustres são diferenciadas. Nestes sistemas como um todo, a variação situou-se em torno de 17\%, incluindo os setores de "águas mortas" ou de baixa hidrodinâmica. No domínio A, a variação foi da ordem de $29 \%$, no B de $17 \%$ e no $\mathrm{C}$ de $15,6 \%$.

No domínio C, observou-se maior número de lagos conectados (113) em relação aos demais domínios de montante, 51 em A e 45 em B. O menor número de conexões dos lagos no domínio $\mathrm{B}$ parece estar condicionado à situação do canal local do Rio Negro.

Assim, para um total de 447 lagos, observouse que $46 \%$ são lagos conectados aos canais do arquipélago durante o período de águas baixas e $54 \%$ ficam isolados neste período.

Esta última observação tem grande relevância para estudos de condições paleoambientais relacionadas aos processos de sedimentação lacustre que podem ter contribuído para a formação do arquipélago de Anavilhanas.

\section{AGRADECIMENTOS}

Os autores agradecem ao $\mathrm{CNPq}$ - Conselho Nacional de Desenvolvimento Científico e Tecnológico, FAPEAM- Fundação de Amparo à Pesquisa do Estado do Amazonas: Projeto BASNE e à CAPES: Projeto Rio Negro TAR. 


\section{REFERÊNCIAS}

ALMEIDA-FILHO, R.; SHIMABUKURO, Y.E.; BEISL, C.H. Assessment of landscape changes in the Anavilhanas Archipelago during the flood peak and drought events in the Rio Negro, central Amazônia, Brazil. Revista Brasileira de Cartografia, v. 68, n. 5, p. 957-964, 2016.

ALVES, N.S. Mapeamento hidromorfodinâmico do complexo fluvial de Anavilhanas. Contribuição aos estudos de Geomorfologia Fluvial de rios amazônicos. São Paulo, 2013. 232p. Tese (Doutorado), Universidade de São Paulo.

ANA, Agência Nacional de Águas. Medição de descarga líquida em grandes rios: Manual Técnico. 2 ed. Brasília: ANA, 94 p., 2014.

ASSAHIRA, C.; PIEDADE, M.T.; TRUMBORE, S.E.; WITTMANN, F.; CINTRA, B.B. L.; BATISTA, E.S.; RESENDE, A.F. \& SCHONGART, J. Tree mortality of a flood-adapted species in response of hydrographic changes caused by an Amazonian river dam. Forest Ecology and Management, v. 396, p. 113-123, 2017.

AYOADE, J.O. Introdução à climatologia para os Trópicos. $4^{\mathrm{a}}$ Ed. São Paulo: Bertrand Brasil, 1996.

CREMON, E.H. Evolução quaternária do Rio Branco - Norte da Amazônia - com base em dados orbitais e geológicos. São José dos Campos, 113p., 2016. Tese (Doutorado), Instituto Nacional de Pesquisas Espaciais, ,

CUNHA, D.F. Evolução Sedimentar do Arquipélago de Anavilhanas no baixo Rio Negro, Amazônia Central. São Paulo, 2017. 59 p. Dissertação (Mestrado em Geociências), Universidade de São Paulo.

EPE. UHE Bem Querer. Disp.em: <http://www.uhebemquerer. com.br/biblioteca-digital/>. Acesso em: $25 \mathrm{fev} 2019$.

FEARNSIDE, P.M. Hidrelétricas na Amazônia: impactos ambientais e sociais na tomada de decisões sobre grandes obras. Manaus: Editora do INPA, 296 p., 2015.

FILIZOLA, N.P. O fluxo de sedimentos em suspensão nos rios da bacia Amazônica Brasileira. Brasília: ANEEL, 63 p., 1999.

FILIZOLA, N. \& GUYOT, J.L. Suspended sediment yields in the Amazon basin: an assessment using the Brazilian national data set. Hydrological Process. v. 23, p. 3207 - 3215, 2009.

FILIZOLA, N. \& GUYOT, J.L. Fluxo de sedimentos em suspensão nos rios da Amazônia. Revista Brasileira de Geociências, v. 41, n. 4, p. 566-576, 2011.

FILIZOLA, N.; GUYOT, J.L.; GUIMARÃES, V. Measuring the discharge of the Amazon River using Doppler technology (Manacapuru, Amazonas, Brazil). Hydrological Processes, v. 23, n. 22, p. 3151-3156, 2009.

FISCH, G.; MARENGO, J.A.; NOBRE, C.A. Uma Revisão Geral sobre o Clima da Amazônia. Acta Amazônica, v. 28, n. 2, p. 101-126, 1998.

GENTIRANA, A.C.V. Contribuições da Altimetria Espacial à Modelagem Hidrológica de Grandes Bacias na Amazônia. Rio de Janeiro, 2009. 299 p. Tese (Doutorado), Universidade Federal do Rio de Janeiro.

GENTIRANA, A.C.V.; BONNET, M.; ROTUNNO FILHO, O. C. \& MANSUR, W. J. Improving hydrological information acquisition from DEM processing in floodplains. Hydrol. Process. V. 23, p. 502-514, 2009.

INPE. Landsat. Disp. em: <http://www.dgi.inpe.br/documen tacao/satelites/Landsat>. Acesso em: 15Jul2019.

JENSEN, J.R. Sensoriamento Remoto do Ambiente: uma perspectiva em recursos terrestres. Tradução de José Carlos Neves Epiphanio (coord.). São José dos Campos, SP: Parêntese, 598 p., 2009.

JUNK, W.J. \& MELLO, J.A.S.N. Impactos ecológicos das represas hidrelétricas na bacia Amazônica brasileira. Estud. av., v. 1.4, n. 8, 1990.

JUNK, W.J.; WITTIMANN, F.; SCHÖNGART, J.; PIEDADE, M.T.F. A classification of the major habitats of Amazonian black-water river floodplains and a comparison with their white-water counterparts. Wetlands Ecol Manage, v. 23, p. 677-693, 2015.

LATRUBESSE, E.M. \& FRANZINELLI, E. The Late Quaternary Evolution Of The Negro River, Amazon, Brazil: Implications For Island And Floodplain Formation In Large Anabranching Tropical Systems. Geomorphology, v. 70, p. 372-397, 2005.

LATRUBESSE, E.M. \& STEVAUX, J.C. The Anavilhanas and Mariuá Archipelagos: Fluvial Wonders from the Negro River, Amazon Basin. In: VIEIRA, B.C.; SALGADO, A.A.R.; SANTOS, L. J. C. (Eds.) Landscapes and Landforms of Brazil. Springer, 267 p., 2015.

LATRUBESSE, E.M.; ARIMA, E.Y.; DUNNE, T.; PARK, E.; BAKER, V.R.; D'HORTA, F.M.; WIGHT, C.; WITTMANN, J.Z.; BAKER, P.A.; RIBAS, C.C.; NORGAARD, R.B.; FILIZOLA, N.; ANSAR, A.; FLYVBJERG, B.; STEVAUX, J.C. Damming the rivers of the Amazon basin. Nature, v. 546, n. 7658, p. 363-369, 2017.

MARENGO, J.A.; TOMASELLA, J.; SOARES, W.R.; ALVES, L.M.; NOBRE, C.A. Extreme climatic events in the Amazon basin. Geophysical Research Letters, 38: 1-5, 2011.

MARENGO, J.A. \& ESPINOZA, J.C. Extreme seasonal droughts and floods in Amazonia: causes, trends and impacts. International Journal of Climatology, v. 36, p. 1033-1050, 2016.

MARINHO, R.R. Integração de dados de campo e sensoriamento remoto no estudo do fluxo de água e matéria do Arquipélago de Anavilhanas, Rio Negro, Amazonas, Brasil. Manaus, 2019. (Tese de Doutorado). Instituto Nacional de Pesquisas da Amazônia.

MARINHO, R.R.; FILIZOLA JUNIOR, N.P.; CARDENAS, E.N.A. Variabilidade hidrológica no arquipélago de Anavilhanas observada por sensoriamento remoto orbital. In: XVIII SIMPÓSIO BRASILEIRO DE SENSORIAMENTO REMOTO - SBSR. Santos - SP, 2017. Resumos expandidos... Santos: INPE, p. 2624-2629., 2017a.

MARINHO, R.R.; SILVA, V.C.; FILIZOLA, N. P. Deteç̧ão da variabilidade do nível do rio Branco (RR) e do rio Jamari (RO) por satélites altimétricos. Acta Geográfica, v. 11, n. 26, p. 102$117,2017 b$.

MEADE, R.H.; RAYOL, J.M.; CONCEIÇÃO, S.C.; NATIVIDADE, J.R.G. Backwater effects in the Amazon River basin of Brazil. Environmental Geology and Water Sciences, v. 18 , n. 2, p. $105-114,1991$

MMA. Sítios Ramsar. Disp. em: http://www.mma.gov.br/areasprotegidas/instrumentos-de-gestao/s\%C3\%ADtios-ramsar. Acessado em: 25Jul2018.

MME/EPE. Plano Decenal de Expansão de Energia 2026. Brasília, MME/EPE, 271p., 2017.

MOLINIER, M.; GUYOT, J.L.; OLIVEIRA, E.; GUIMARÃES, V. Les Régimes Hydrologiques de L'amazone et de ses Affluents. In: CHEVALLIER, P. \& POUYAUD, B. (eds.) L'hydrologie Tropicale: Géoscience et Outil Pour le Développement. Paris: IAHS, v. 238, p. 209-222, 1996.

MUNIZ, L.S.; SILVA, V.C.; MARINHO, R.R. \& FILIZOLA JUNIOR, N. P. Análise multitemporal da seca de 2016 no Rio Branco: uma avaliação preliminar da variabilidade hidrológica. In: SIMPÓSIO BRASILEIRO DE SENSORIAMENTO REMOTO, XVIII, Santos, 2017. Resumos expandidos...Santos: INPE, 2017, p. 3098-3105.

PIEDADE, M.T.F.; JUNK, W.J.; ADIS, J.; PAROLIN, P. Ecologia, zonação e colonização da vegetação arbórea das ilhas de Anavilhanas. São Leopoldo: Instituto Anchietano de Pesquisas, Pesquisas Botânicas, n 56, p. 117-144, 2005.

PRANCE, G.T. A terminologia dos tipos de florestas amazônicas sujeitas a inundação. Acta Amazônica, v. 10, n. 3, p. 495-504, 1980.

SOMBROEK, W. Spatial and Temporal Patterns of Amazon Rainfall. Journal of the Human Environment, v. 30, n. 7, p. 
388-396, 2001

USGS. Landsat Missions. Disp. em: <https://www.usgs.gov/ land-resources/nli/Landsat/Landsat-8>. Acesso em: 18Jul2019. ZANI, H. Detecção e caracterização do megaleque Viruá (RR) com dados multisensores e geológicos: influência nos padrões atuais de vegetação. São José dos Campos, 2013. 145 p. Tese (Doutorado (Programa de Pós-Graduação em Sensoriamento Remoto), Instituto Nacional de Pesquisas Espaciais.
ZANI, H.; MARINHO, R.R.; GAVLAK, A.A. Avaliação de métodos para extração de corpos d'água e áreas inundadas em imagens Landsat-TM. In: SIMPÓSIO NACIONAL DE GEOMORFOLOGIA, VIII, Belo Horizonte, 2010. Anais.. Belo Horizonte. CD-ROM.

Submetido em 10 de agosto de 2019 Aceito para publicação em 21 de abril de 2020 